\section{B-lymphocyte reconstitution after repeated rituximab treatment in a child with steroid-dependent autoimmune hemolytic anemia}

\author{
Annelieke A.A. van der Linde, 1 \\ Ellen J.H. Schatorjé,1 Annemieke M. van \\ der Weij, ${ }^{1}$ Eugenie F.A. Gemen, ${ }^{2}$ \\ Esther de Vries 1 \\ 1Department of Pediatrics; \\ 2Laboratory of Hematology and Clinical \\ Chemistry, Jeroen Bosch Hospital, \\ 's-Hertogenbosch, The Netherlands
}

\section{Abstract}

We report the detailed long-term reconstitution of B-lymphocyte subpopulations, immunoglobulins, and specific antibody production after two courses of rituximab in a young, previously healthy girl with steroid-dependent autoimmune hemolytic anemia. B-lymphocyte subpopulations were surprisingly normal directly after reconstitution. However, there was a slower reconstitution after the second rituximab course, especially of non-switched and switched memory B-lymphocytes, and a temporary decline in IgM below age-matched reference values.

\section{Introduction}

Rituximab is increasingly used in the treatment of various hematological malignancies and, more recently, autoimmune diseases like autoimmune hemolytic anemia (AIHA). ${ }^{1}$ Rituximab is a monoclonal antibody that reacts with the CD20 antigen, which is expressed on pre-B and mature B-lymphocytes, but not on plasma cells. B-lymphocytes play an important regulatory and potentially pathogenic role in autoimmune diseases through antibody-independent mechanisms like antigen presentation, T-lymphocyte activation, and the production of cytokines and chemokines.2,3 They are also the precursors of (auto)antibody-producing plasma cells. Depletion of B-lymphocytes is therefore likely to interfere with the complex (auto)immune process, but the exact mechanism of its effect on autoimmune diseases is not yet fully understood. 4

Treatment with rituximab results in a rapid and sustained depletion of B-lymphocytes. There are detailed reports on the rate and phenotype of B-lymphocyte subpopulation recovery after rituximab treatment in adults:5-12 after Bcell depletion immature B-lymphocytes reap- pear first, followed by naïve B-lymphocytes; CD27+ memory B-lymphocytes may remain reduced up to 2 years after rituximab treatment. 5,8

It would be expected that depletion of CD20+ B-lymphocytes has direct effects on antibody production, and indirect effects on cellular immunity. Indeed, hypogammaglobulinemia requiring substitution was recently described in a child with repeated rituximab treatment for idiopathic thrombocytopenic purpura and underlying autoimmune lymphoproliferative disease. ${ }^{13}$ However, until now large numbers of serious infectious complications of rituximab treatment have not been described, ${ }^{4}$ perhaps because antibody-producing plasma cells are spared.

In this paper, we give a detailed description of the reconstitution of B-lymphocyte subpopulations, immunoglobulins (Igs), and specific antibody production after repeated treatment with rituximab in a young, previously healthy, girl with steroid-dependent AIHA.

\section{Materials and Methods}

\section{Patient}

In August 2004, a previously healthy 13months-old girl presented in our hospital with AIHA which turned out to be steroid-dependent. Aspecific IgG autoantibodies were strongly positive. In August 2005, she was treated with rituximab $\left(4 \times 375 \mathrm{mg} / \mathrm{m}^{2}, 1\right.$ week apart). Human anti-chimeric antibodies (HACAs) were measured once and found negative. Subsequently, steroids could be tapered and stopped 11 months after the first rituximab treatment, in July 2006. A few weeks later, she suffered a relapse and steroids were restarted, and a second course with 4 gifts of rituximab (375 mg/m², 1 week apart) was administered. Hereafter, the steroid dose was slowly reduced again, and 11 months after the second treatment with rituximab, in July 2007, at the age of 4 years, steroids were stopped completely. In 2011 , at almost 8 years of age, there were still no signs of relapse. Aspecific IgG autoantibodies remained negative. She did not suffer from any significant infections. The clinical course of this girl is illustrated in Figure 1.

Preceding rituximab treatment, but while on steroids, vaccination status was optimised using Prevenar twice (Wyeth) followed by Pneumovax (Sanofi Pasteur MSD) for S. pneumoniae, and NeisVacC (Baxter) and MeningovaxAC (Sanofi Pasteur MSD) for $S$. meningitidis. This was considered important, because both rituximab and prolonged steroid treatment might compromise immunity. After 2.5 years, Pneumovax and Mencevax ACWY (Glaxo Smith Kline) vaccinations were given. Diphtheria - tetanus - inactivated poliomyelitis
Correspondence: Esther de Vries, Dept. of Pediatrics, Jeroen Bosch Hospital, P0 Box 90153, $5200 \mathrm{ME}$ 's-Hertogenbosch, The Netherlands.

Tel. +31.73 .5532458 - Fax +31.73 .5532948 .

E-mail: e.d.vries@jbz.nl.

Key words: autoimmune hemolytic anemia, rituximab, child, immune reconstitution, B-lymphocytes.

Received for publication: 12 May 2011.

Revision received: 18 September 2011

Accepted for publication: 26 October 2011.

This work is licensed under a Creative Commons Attribution NonCommercial 3.0 License (CC BYNC 3.0).

(C) Copyright A.A.A. van der Linde et al., 2011

Licensee PAGEPress, Italy

Pediatric Reports 2011; 3:e28

doi:10.4081/pr.2011.e28

(DTP-NVI) vaccination was given at the age of four, according to the regular Dutch immunisation schedule (Figure 1).

Peripheral blood samples were taken at multiple time points $(\mathrm{t}=0,8,14,21,56,110,202$, $321,383,396,403,410,417,446,530,614,718$, 816, 1085 days after the first rituximab dose, indicated with arrows in Figure 1) to establish the reconstitution of B-lymphocyte subpopulations, Ig titers and specific antibody production.

\section{Immunophenotyping}

Four-color flow cytometric immunophenotyping was performed using the lyse and wash whole-blood method. Aliquots of ethylene diaminetetra-acetic (EDTA) blood $(50 \mu \mathrm{L})$ were incubated for $15 \mathrm{~min}$ at room temperature in the dark with the following monoclonal antibodies: isotype control gamma 1 conjugated to fluorescein isothiocyanate (FITC) (Becton Dickinson, San Jose, CA, USA (BD)), isotype control gamma 2a conjugated to phycoerythrin (PE) (BD), CD3-FITC (Immuno Quality Products, Groningen, The Netherlands (IQP)), CD3 conjugated to allophycocyanin (APC) (BD), CD3 conjugated to PE-Cyanin5 (PE-Cy5) (Coulter Immunotech, Marseille, France (CI)), CD4-PE (IQP), CD4-PE-Cy5 (CI), CD5-FITC (BD), CD8-PE (IQP), CD8 conjugated to peridinin chlorophyll protein cyanin 5.5 (PerCPCy5.5) (BD), CD10-APC (BD), CD16/56-PE (BD), CD19-PE (BD), CD19-PE-Cy5 (CI), CD19-PerCP-Cy5.5 (BD), CD20-FITC (BD), CD21-PE (BD), CD25-FITC (CI), CD27-FITC (BD), CD27-PE (BD), CD45RA-PE (CI), CD45R0-FITC (BD or IQP), IgD-FITC (SouthernBiotech, Birmingham, USA), and IgM-FITC (Sanofi Pasteur Marnes-LaCoquette, France). To eliminate immunoglobulins, aliquots destined for anti-IgM and antiIgD were washed three times before staining. 
Erythrocytes were lysed using FACSLysing solution (BD) according to the manufacturer's protocol. The cells were washed twice with $0.5 \%$ bovine serum albumin/phosphatebuffered saline. Analysis was performed using CellQuest ProSoftware (BD) on a FACSCalibur flowcytometer (BD), which was calibrated according to the guidelines of Kraan et al.14 The absolute leukocyte count $\left(\times 10^{9} / \mathrm{L}\right)$ was determined on a Sysmex XE-2100 hematology analyzer (Sysmex, Kobe, Japan). The absolute number $\left(\times 10^{9} / \mathrm{L}\right)$ of a lymphocyte subpopulation was calculated by multiplying the calculated absolute lymphocyte size $(\times 109 / \mathrm{L})$ with the relative size of the lymphocyte subpopulation (\%) within the lymphocyte gate. The values were compared to reference values in healthy children derived from our laboratory.

\section{Immunoglobulins}

IgG, IgA, IgM, and IgG-subclasses were determined by standard nephelometric methods (BNProspec, Dade Behring, The Netherlands). Specific antibody responses to pneumococcal vaccination were determined by ELISA, diphtheria and tetanus antitoxin antibodies with a toxin-binding inhibition assay. 15,16

\section{Results}

As expected, all peripheral blood B-lymphocyte subpopulations disappeared rapidly upon treatment with rituximab (Figure 2), T-lymphocyte subpopulation and NK-cell counts were not affected (Table 1). After the first rituximab course, B-cells reappeared at $\mathrm{t}=110$ days, after the second course they reappeared later, at $\mathrm{t}=614$ (218 days after the second rituximab course). The reappearing cells were mainly naive cells (CD19+IgD+CD27-), around one third were $\mathrm{CD}^{+}$(Figure 2). After the second course, both non-switched $(\mathrm{CD} 19+\operatorname{IgD}+\mathrm{CD} 27+)$ and switched (CD19+IgDCD27+) memory B-lymphocytes reappeared later than after the first course (at $\mathrm{t}=110$ days after the first course, together with the naive cells, and at 320 days after the second course, which is 102 days after the first naive cells, at $\mathrm{t}=718$ days (Figure 2). However, switched memory B-lymphocytes were within the agelimits of normal from the moment they reappeared (Table 1). CD21+ cells (IgM- and IgM+) repopulated in the same manner as the other B-lymphocyte subpopulations.

IgG, IgA, and IgG-subclass levels were unaffected by the rituximab treatment (Table 1), but after the second course a temporary decrease in $\operatorname{IgM}$ was found $(0.48 \mathrm{~g} / \mathrm{l}$ at $\mathrm{t}=446$ days; $0.23 \mathrm{~g} / \mathrm{l}$ at $\mathrm{t}=530$ days; $0,6 \mathrm{~g} / \mathrm{l}$ at $\mathrm{t}=614$ days), as has been described before.17,18 After both rituximab treatments prednisone was used every other day and slowly tapered until it could be stopped. After the first treatment with rituximab the dosage of prednisone was slightly higher. During that time we didn't see an effect on immunoglobulins or significant infections. Vaccination responses before the first rituximab course were normal; booster responses after the second course (after $\mathrm{t}=$ 1085 days) were normal as well (Table 1), despite the fact that she had been on steroids during the first round of vaccinations.

\section{Discussion}

We followed a girl with steroid-dependent AIHA who was treated with 4 gifts of rituximab twice. She repopulated mainly with naive Blymphocytes, around one third $\mathrm{CD}^{+}$, as could be expected for her age. Interestingly, her Blymphocytes returned to normal faster than described before in both adults ${ }^{5-7}$ and children,17,18 but these children had underlying diseases that may have influenced the reconstitution. She did not suffer any significant infections, and responded well to vaccination, despite her prolonged steroid use.

During repopulation memory B-lymphocytes peaked just before the relapse in our patient. Increasingly, early relapse of autoimmune diseases like rheumatoid arthritis or SLE are reported in adult patients with a higher number of memory B-lymphocytes in early reconstitution in comparison to patients with later or no relapse. $5,8,10$ Our case suggests that this relation may also exist in children.

After the second rituximab treatment, the reconstitution was somewhat slower in our patient. This has been described by others, 4,13 suggesting that multiple rituximab courses

Table 1. Absolute values of lymphocyte subpopulations in comparison with control values from healthy age-matched children.

\begin{tabular}{|c|c|c|c|c|c|}
\hline time in days & $\mathrm{t}=0$ & $t=110$ & $t=396$ & $\mathrm{t}=614$ & $\mathrm{t}=718$ \\
\hline $\begin{array}{l}\text { CD19+ } \\
\text { total B-lymphocytes }\end{array}$ & $\begin{array}{l}0.86^{*} \\
0.76(0.3-2.8)^{* *}\end{array}$ & $\begin{array}{l}0.34 \\
0.76(0.3-2.8)\end{array}$ & $\begin{array}{l}0.54 \\
0.49(0.3-0.7)\end{array}$ & $\begin{array}{l}0.33 \\
0.49(0.3-0.7)\end{array}$ & $\begin{array}{l}0.54 \\
0.49(0.3-0.7)\end{array}$ \\
\hline $\begin{array}{l}\text { CD19+CD5+ } \\
\text { CD5+ B-lymphocytes }\end{array}$ & $\begin{array}{l}0.54 \\
0.39(0.1-1.3)\end{array}$ & $\begin{array}{l}0.14 \\
0.39(0.1-1.3)\end{array}$ & $\begin{array}{l}0.08 \\
0.15(0.0-0.4)\end{array}$ & $\begin{array}{l}0.038 \\
0.15(0.0-0.4)\end{array}$ & $\begin{array}{l}0.16 \\
0.15(0.0-0.4)\end{array}$ \\
\hline $\begin{array}{l}\text { CD19+CD10+ } \\
\text { Immature B-lymphocytes }\end{array}$ & $\begin{array}{l}0.18 \\
0.24(0.09-0.87)\end{array}$ & $\begin{array}{l}0.07 \\
0.24(0.09-0.87)\end{array}$ & $\begin{array}{l}0.48 \\
0.12(0.04-0.25)\end{array}$ & $\begin{array}{l}0.33 \\
0.12(0.04-0.25)\end{array}$ & $\begin{array}{l}0.13 \\
0.12(0.04-0.25)\end{array}$ \\
\hline $\begin{array}{l}\text { CD19+IgD+CD27- } \\
\text { naive B-lymphocytes }\end{array}$ & $\begin{array}{l}0.74 \\
0.61(0.24-2.61)\end{array}$ & $\begin{array}{l}0.28 \\
0.61(0.24-2.61)\end{array}$ & $\begin{array}{l}0.36 \\
0.37(0.20-0.59)\end{array}$ & $\begin{array}{l}0.30 \\
0.37(0.20-0.59)\end{array}$ & $\begin{array}{l}0.47 \\
0.37(0.20-0.59)\end{array}$ \\
\hline $\begin{array}{l}\text { CD19+IgD+CD27+ } \\
\text { non-switched memory } \\
\text { B-lymphocytes }\end{array}$ & $0.04(0.01-0.12)$ & $0.04(0.01-0.12)$ & $0.04(0.02-0.1)$ & $0.04(0.02-0.1)$ & $\begin{array}{l}0.027 \\
0.04(0.02-0.1)\end{array}$ \\
\hline $\begin{array}{l}\text { CD19+IgD-CD27+ } \\
\text { switched memory } \\
\text { B-lymphocytes }\end{array}$ & $0.022(0.005-0.03)$ & $0.022(0.005-0.03)$ & $0.040(0.012-0.13)$ & $0.040(0.012-0.13)$ & $\begin{array}{l}0.032 \\
0.040(0.012-0.13)\end{array}$ \\
\hline $\begin{array}{l}\text { CD3+ cells } \\
\text { (T lymphocytes) }\end{array}$ & $\begin{array}{l}2.79 \\
2.5(0.7-8.8)\end{array}$ & 2.64 & $\begin{array}{l}1.11 \\
1.9(0.85-4.3)\end{array}$ & $\begin{array}{l}2.58 \\
1.9(0.85-4.3)\end{array}$ & $\begin{array}{l}2.12 \\
1.9(0.85-4.3)\end{array}$ \\
\hline NK cells & $\begin{array}{l}0.28 \\
0.47(0.055-4.0)\end{array}$ & 0.18 & $\begin{array}{l}0.44 \\
0.18(0.061-0.51)\end{array}$ & $\begin{array}{l}0.32 \\
0.18(0.061-0.51)\end{array}$ & $\begin{array}{l}0.24 \\
0.18(0.061-0.51)\end{array}$ \\
\hline $\operatorname{Ig} \mathrm{G}^{* * *}$ & 5.8 & 6.2 & 8.6 & 5.9 & 7.2 \\
\hline $\operatorname{Ig} A^{* * *}$ & 0.52 & 0.68 & 0.92 & 0.88 & 1.23 \\
\hline $\operatorname{Ig}^{* * *}$ & 1.07 & 0.65 & 1.56 & 0.6 & 0,54 \\
\hline
\end{tabular}




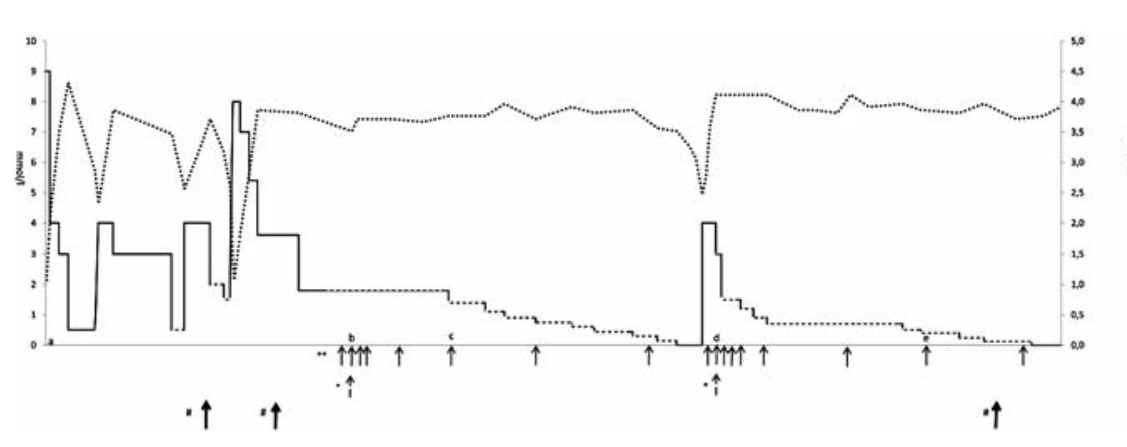

Figure 1. Time schedule of patient's history. Dotted line: hemoglobin (mmol/L). Prednisone $(\mathrm{mg} / \mathrm{kg} /$ day) uninterrupted line; prednisone $(\mathrm{mg} / \mathrm{kg}$ every other day) interrupted line. Arrows: ${ }^{*}$ rituximab treatment; ${ }^{* *}$ blood sample $(\operatorname{resp} t=0,8,14,21,56,110$, $202,321,383,396,403,410,418,446,530,614,718,817,1085$ days after the first rituximab dose); \# vaccination. a: first presentation with autoimmune hemolytic anemia (August 2004); b: first treatment with rituximab (August 2005); c: recovery of B-lymphocytes (day 110 after first rituximab treatment); $d$ : relapse and second treatment with rituximab (July 2006); e: recovery of B-lymphocytes (day 218 after $2^{\text {nd }}$ rituximab treatment). Timeline stops in July 2007 when steroids are stopped.

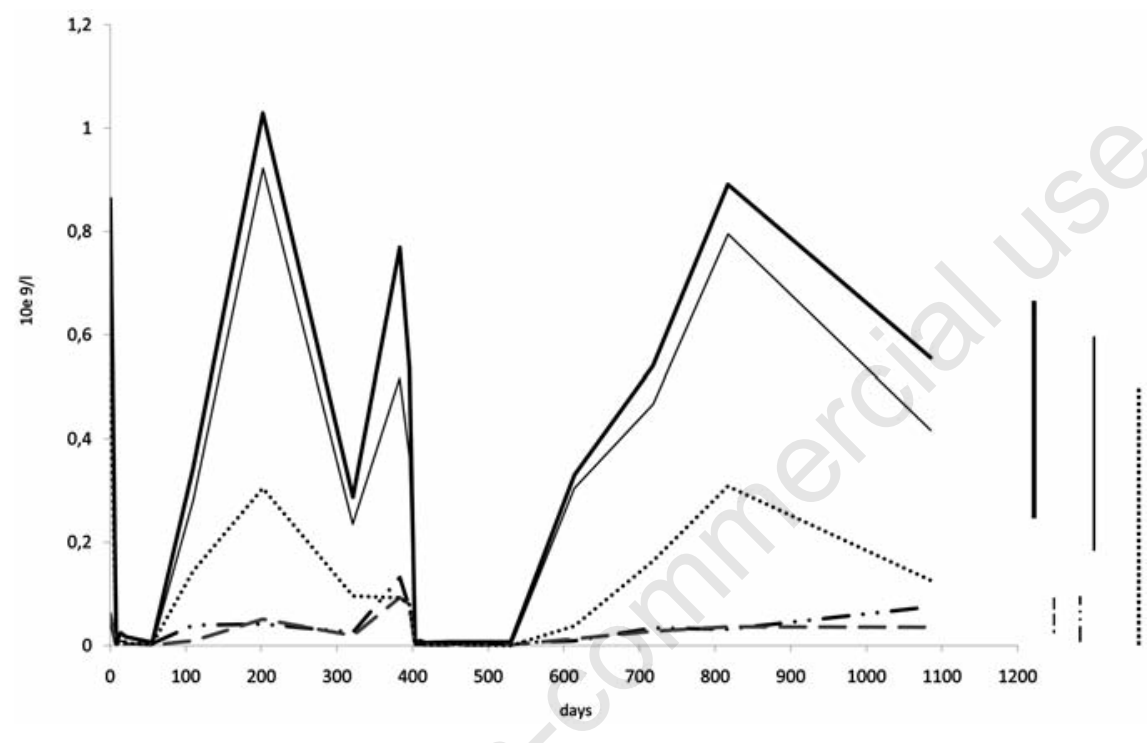

Figure 2. B-lymphocyte subpopulations. Timeline starts in August 2005, directly after first rituximab treatment, shows depletion after $2^{\text {nd }}$ rituximab treatment and continues until roughly 2.5 years remission. Total B-lymphocytes (CD19+) bold line; naive B-lymphocytes (CD19+IgD+CD27-) narrow line. Switched memory B-lymphocytes $\left(\mathrm{CD} 19+\operatorname{IgD}-\mathrm{CD} 27^{+}\right)$score-dot-dot; non-switched memory B-lymphocytes $\left(\mathrm{CD} 1{ }^{+}+\mathrm{IgD}^{+} \mathrm{CD}^{2} 7^{+}\right)$interrupted line; $\mathrm{CD}^{+} \mathrm{B}$-lymphocytes dotted line. Reference values determined in healthy children in our laboratory are shown as vertical lines.

may eventually lead to secondary antibody deficiency and infectious complications. Future studies in larger numbers of children are needed to analyze this further.

\section{References}

1. Quartier P, Brethon B, Philippet P, et al. Treatment of childhood autoimmune haemolytic anaemia with rituximab. Lancet 2001;358:1511-13.

2. Kessel A, Rosner I, Toubi E. Rituximab: beyond simple B cell depletion. Clinic Rev
Allergy Immunol 2008;34:74-9.

3. Stamatis-Nick CL, Sfikakis PP. Rituximabinduced B cell depletion in autoimmune diseases: Potential effects on T cells. Clin Imm 2008;127:280-5.

4. Cooper N, Arnold DM. The effect of rituximab on humoral and cell mediated immunity and infection in the treatment of autoimmune diseases. B J Haematol 2010;149:3-13.

5. Leandro MJ, Cambridge G, Ehrenstein MR, Edwars JC. Reconstitution of peripheral blood B cells after depletion with rituximab in patients with rheumatoid arthritis. Arthritis Rheum 2006;54:613-20.
6. Roll P, Palanichamy A, Kneitz C, et al. Regeneration of B cell subsets after transient B cell depletion using anti-CD20 antibodies in rheumatoid arthritis. Arthritis Rheum 2006;54:2377-86.

7. Sidner RA, Book BK, Agarwal A, et al. In vivo human B-cell subset recovery after in vivo depletion with rituximab, anti-human CD20 monoclonal antibody. Human Antibodies 2004;13:55-62.

8. Roll P, Dörner T, Tony, HP. Anti-CD20 therapy in patients with rheumatoid arthritis. Predictors of response and B cell subset regeneration after repeated treatment. Arthritis Rheum 2008;58:1566-75.

9. Pers J0, Daridon C, Bendaoud B et al. Bcell depletion and repopulation in autoimmune diseases. Clinic Rev Allergy Immunol 2008;34:50-5.

10 Anolik JH, Barnard J, Owen T et al. Delayed memory $B$ cell recovery in peripheral blood and lymphoid tissue in systemic lupus erythematosus after B cell depletion therapy. Arthritis Rheum 2007;56:3044-56.

11 Abulayha AM, Tabal SA, Shawesh EI et al. Depletion of peripheral blood B cells with rituximab and phenotype characterization of the recovering population in a patient with follicular lymphoma. Leuk Res 2010;34:307-11.

12 Anolik JH, Friedberg JW, Zheng B et al. B cell reconstitution after rituximab treatment of lymphoma recapitulates B cell ontogeny. Clin Immun 2007;122:139-145.

13 Cooper N, Davies EG, Thrasher AJ. Repeated courses of rituximab for autoimmune cytopenias may precipitate profound hypogammaglobulinaemia requiring replacement intravenous immunoglobulin. B J Haematol 2009;146:113-24.

14 Kraan J, Gratama JW, Keeney M, D'Hautcourt JL. Setting up and calibration of a flow cytometer for multicolor immunophenotyping. J Biol Regul Homeost Agents 2003;17:223-33

15 Hendriksen CF, van der Gun JW, Kreeftenberg JG. Combined estimation of tetanus and diphtheria antitoxin in human sera by the in vitro Toxin-Binding Inhibition (ToBI) test. J Biol Stand 1989;17:191-200.

16 De Melker HE, Berbers GA, Nagelkerke NJ et al. Diphtheria antitoxin levels in the Netherlands: a population-based study. Emerg Infect Dis 1999;5:694-700.

17 Kamei K, Ito S, Nozu K et al. Single dose of rituximab for refractory steroid dependent nephrotic syndrome in children. Pediatr Nephrol 2009;24:1321-8.

18 Zarkhin V, Li L, Kambham N, et al. A randomized prospective trial of rituximab for acute rejection in pediatric renal transplantation. Am J Transplant 2008;8:2607-17. 